\title{
Nursing Care in Dermatologic Oncology: a Qualitative Study
}

\author{
Jordan Sibeoni $^{1,2}$ (1) Marine Marc ${ }^{3,4} \cdot$ Marion Lagaude $^{3,4} \cdot$ Massimiliano Orri $^{2,5} \cdot$ Laurence Verneuil $^{2}$. \\ Anne Revah-Levy ${ }^{1,2}$
}

Published online: 13 July 2019

(C) American Association for Cancer Education 2019

\begin{abstract}
Nurses in hospital dermatology departments must increasingly provide care for patients with skin cancer. Although the experience of oncology nurses in numerous specialties has been widely explored, no study has focused on the experience of nurses in dermatologic oncology. We aimed to explore how nurses experience their care for patients with skin cancer. This is an inductive, exploratory study employing semi-structured interviews and focus groups with nurses, followed by thematic analysis. The study included purposive sample of 14 nurses practicing in different sectors of this dermatology department. Data were collected via two focus groups of six nurses each and 14 individual, semi-structured interviews, both using a researcher-developed interview guide. Interviews were transcribed and analyzed with thematic analysis. The most illustrative quotes were translated into English. Nurses' experiences of providing care in dermatologic oncology are organized around two themes: (1) their practices for these patients and (2) their management of emotional distress as the major issue in care, especially at night. Our results show the predominant place of relationships with patients in nurses' practices and of their emotional distress due to their closeness to the patients. Specific and original aspects have also been demonstrated with practical implications to be drawn for nurses' supportive care role: the distress engendered by the specific and harrowing experience of nurses dealing with skin cancer, which can be both seen and smelled.
\end{abstract}

Keywords Qualitative research $\cdot$ Nursing care $\cdot$ Nurses $\cdot$ Supportive care $\cdot$ Skin cancer

Laurence Verneuil and Anne Revah-Levy contributed equally to this work.

Electronic supplementary material The online version of this article (https://doi.org/10.1007/s13187-019-01573-8) contains supplementary material, which is available to authorized users.

Jordan Sibeoni

Jordansib@hotmail.com

1 Service Universitaire de Psychiatrie de l'Adolescent, Argenteuil Hospital Centre, 69 rue du LTC Prud'hon, 95107 Argenteuil, France

2 ECSTRRA Team, UMR-1153, Inserm, Université de Paris, F-75010, Paris, France

3 Department of Dermatology, Caen University Hospital, F-14033 Caen, France

4 Université de Caen Normandie, Medical School, F-14000 Caen, France

5 McGill Group for Suicide Studies, Douglas Mental Health University Institute, Department of Psychiatry, McGill University, Montreal, Canada

\section{Introduction}

Nurses in hospital dermatology departments work increasingly with patients with skin cancer. The incidence of most of these cancers has increased in recent decades [1], including those of squamous-cell and basal-cell carcinoma [2] and cutaneous melanoma, the incidence rate of which has quintupled among white populations over the past 30 years [3]. Prognosis varies according to the type of cancer and its stage at diagnosis. The 5-year survival rate for metastatic melanoma is $15 \%$, and the median survival time after multiple metastases ranges from 6 to 9 months [4]; when treated with new immunotherapy methods, the median overall survival is 23 months [5]. Melanoma is among the cancers with the highest overall mortality rates. Moreover, even when their prognosis is favorable, as it is for T cell lymphomas, these cancers strongly affect the quality of life of patients and their families [4].

Throughout cancer patients' healthcare pathway, nurses continuously serve as a resource person for them and their families and must often face the patients' deaths [6]. An abundant qualitative literature explores the experience of nurses providing care to patients with cancer, dealing with a wide variety of issues: nurses' moral questions about administering 
chemotherapy [7], their difficulties of communication with physicians, and their concern about patients' pain, sexual function, and spirituality [8-10]. Nurses have also underlined the relational dimension of their work providing supportive care: the positive impact of establishing a helping and trusting relationship with the patient $[11,12]$, but also the painful experience and emotional burden inherent in working with them [13].

None of these studies have focused on the experience of nurses in dermatologic oncology. The aim of our study was to assess the specific experience of these nurses as it reflects the specificity of skin cancer.

\section{Methods}

\section{Setting}

This exploratory single-center study took place in the Caen University Hospital Center dermatology department within three work settings: outpatient clinic (participation in the "diagnosis report" visits, work-ups to assess staging or extension of disease, and chemotherapy), day hospital (chemotherapy), and full-time in-patient unit (management of inpatients with advanced-stage skin cancer and of the side effects of their systemic treatments, or the implementation of palliative care). The Paris-Descartes University review board (CERES) approved the research protocol. All participants provided written informed consent. Theoretical framework fits into constructivist paradigm and the study, complied with the COREQ guidelines [14], used a phenomenological approach.

\section{Sampling and Participants}

Sampling was purposive that is selective and deliberate, with maximum variation, (i) to include nurses who differed in age, years of experience in dermatology, and work settings and (ii) to challenge the findings continuously by including participants who might invalidate what was previously found [15]. The researchers explained the study design in detail to all nurses in the department and offer them three modes of participation: focus group, individual interview, or both. The study included all nurses that agreed to participate. Two nurses refused to participate, one for personal reasons and the other for lack of time.

\section{Data Collection}

Data came from two focus-groups and 14 individual interviews. Both focus groups and individual interviews used an unstructured, open-ended approach [16] with only one introductory prompt: "can you tell us about your daily life, your practice, and your lived-experience caring for patients with cancer?"
Offering two data collection methods increased the chance of nurses agreeing to participate. Focus groups were used to create a process of sharing and comparing among participants while individual interviews were thought to obtain rich and detailed personal data of the nurse's lived-experience. Triangulation of data-collection methods - the use of multiple methods of data collection to develop a comprehensive understanding of phenomena - is a rigor criteria in qualitative research [17]. The combination between individual interviews and focus groups has already been used in qualitative nursing research and has shown to strengthen the quality of the studies, especially by enhancing data richness [18].

Our sample size was determined according to the principle of theoretical sufficiency [19]. That is, data collection and analysis were completed when the researchers determined that the themes obtained offered a sufficient explanatory framework for the data collected. Focus groups lasted around $2 \mathrm{~h}$ and each interview approximatively $1 \mathrm{~h}$. They were conducted by a pair of experimented researchers (JS, a psychiatrist and MO, a clinical psychologist, and MM and ML, dermatologists), from September through December 2015. The interviews, which have been anonymized, were recorded and transcribed word-for-word, including the participants' expressive nuances. The transcript thus obtained was then analyzed.

\section{Analysis}

We used thematic analysis to explore the data [20]. This method can be used to analyze data from both focus-groups and individual interviews. It enables the identification, analysis, and reporting of the themes within the data. Our thematic analysis was data-driven and used an inductive approach: a process of coding the data without any reference to theoretical notions or researcher's preconceptions. Table 1 summarizes the different stages of our thematic analysis. This process is dynamic and iterative, with each new transcript leading to the collection of additional data and to their subsequent analysis. The objective was to identify the similarities and the differences between the accounts of each participant. The researchers were thus led to discern the recurrent patterns but also to integrate the new issues that emerged from the analysis. Three researchers (JS, MO, and ARL) independently performed this analysis with Nvivo 11 software to ensure its validity by improving its relevance and consistency. Moreover, results were regularly debated during research group meetings. In cases of disagreements, the discussion continued until a consensus was reached. In the results that follow, extracts of the transcripts have been selected to exemplify the themes described. All personal information has been removed, to protect the confidentiality of the participants. The transcripts have been freely translated into English for the sole purposes of this article. 
Table 1 Process of inductive thematic analysis

\begin{tabular}{|c|c|c|}
\hline & Activities & Rationale \\
\hline Stage 1 & $\begin{array}{l}\text { Repeatedly read each } \\
\text { transcript, as a whole }\end{array}$ & $\begin{array}{l}\text { Develop a global picture of } \\
\text { the interview and become } \\
\text { familiar with the } \\
\text { interviewee's verbal style } \\
\text { and vocabulary. } \\
\text { Each new reading of the } \\
\text { transcript might also } \\
\text { provide new perspectives. }\end{array}$ \\
\hline Stage 2 & $\begin{array}{l}\text { Code the transcript by making } \\
\text { notes that correspond to the } \\
\text { fundamental units of } \\
\text { meanings }\end{array}$ & $\begin{array}{l}\text { Take descriptive notes using } \\
\text { the participant's own words }\end{array}$ \\
\hline Stage 3 & $\begin{array}{l}\text { Take conceptual notes } \\
\text { through processes of } \\
\text { condensation, abstraction, } \\
\text { and comparison of the } \\
\text { initial notes. }\end{array}$ & $\begin{array}{l}\text { Categorize initial notes and to } \\
\text { reach a higher level of } \\
\text { abstraction }\end{array}$ \\
\hline Stage 4 & $\begin{array}{l}\text { Identify initial themes } \\
\text { Provide text quotes that } \\
\text { illustrate the main ideas of } \\
\text { each theme }\end{array}$ & $\begin{array}{l}\text { Themes are labels that } \\
\text { summarize the essence of a } \\
\text { number of related } \\
\text { conceptual notes. They are } \\
\text { used to capture the } \\
\text { experience of the } \\
\text { phenomenon under study. }\end{array}$ \\
\hline Stage 5 & $\begin{array}{l}\text { Identify recurrent themes } \\
\text { across transcripts } \\
\text { And to produce a coherent } \\
\text { ordered } \\
\text { table of the themes, gathered } \\
\text { into domains of experience }\end{array}$ & $\begin{array}{l}\text { Move from the particular to } \\
\text { the shared across multiple } \\
\text { experiences. Recurrent } \\
\text { themes reflect a shared } \\
\text { understanding of the } \\
\text { phenomena among all } \\
\text { participants. } \\
\text { During this more analytic } \\
\text { stage, the researchers try to } \\
\text { make sense of the } \\
\text { associations between the } \\
\text { themes found. }\end{array}$ \\
\hline
\end{tabular}

\section{Results}

Fourteen nurses participated in this study, in two focus groups of six nurses each and 14 individual interviews. Table 2 summarizes the participants' characteristics. The nurses' experience of caring for dermatologic oncology patients was organized around two themes: (1) the nurses' practices with patients with skin cancer and (2) the role and impact of emotional distress in these practices. The results are presented below and relevant quotations from the transcripts in Table 3.

\section{Nurses' Practices: Seeing, Smelling, Doing, Interacting, Being}

The nurses' practices with these patients could be separated into five basic units: seeing, smelling, doing, interacting, and being.

\section{Seeing}

The nurses described having to look at the frightening, ravaged appearance of cancer and their feeling of dread on seeing these prominent and unavoidable lesions on the face and other body parts (Q1, Q2).

Q2: RN7 II: "Everything that's visible, that is, the face... it's more... terrible because what's left, at the most, you can put a bandage, you can't see it anymore... You cover the face, it's ok."

\section{Smelling}

They explained that they sometimes could not contain their reactions on exposure to the stench of these lesions (Q3). They experienced their reaction as an inability to restrain their emotions. The characteristics of the recurrent odor in dermatology, although not specific to cancer, was here directly associated with cancer and its prognosis (Q4).

Q3: RN5 FG1: "What's a problem is when there's a smell, when it really smells awful... You can't help but grimace."

\section{Doing}

Some nurses underlined the technical aspect of their work (Q5, Q6). Nonetheless, technical care that involves touching the patient and these cancer wounds occupied a particular place in their experience. On the one hand, they mentioned the need to put a physical distance between the affected areas and themselves during the care process (Q7). On the other hand, these tasks can enable them to move beyond their initial reactions to seeing and smelling the tumors and reaffirm their role as healthcare providers $(\mathrm{Q} 8, \mathrm{Q} 9)$.

Q6/RN 7 II: "They come to do chemo, it's the technical procedures first!"

\section{Interacting}

All participants emphasized the relational dimension of nursing. Most had an important relational role, both as the patient's main interlocutor and as a witness and mediator in the patient's relationships with family and physicians. Most described closeness to the patients, perceiving themselves as the staff person to whom the patient felt the closest (Q10). They provided support by their presence and their attention (Q11). This relational concern extended to the patients' families and friends. The nurses felt they were special witnesses to the relationships related to care (Q12). They sometimes reported communication difficulties between the patient and the physician due to the patient's inhibition toward the doctor but also to the fear of the information the physician might deliver to the patient (Q13, Q14). They were privileged witnesses to the communication between patient and their 
Table 2 Nurses' characteristics

\begin{tabular}{|c|c|c|c|c|c|}
\hline & Gender & Age & $\begin{array}{l}\text { Years of experience } \\
\text { in dermatology }\end{array}$ & Work setting & Participation \\
\hline RN 1 & F & 33 & 11 & OPDH & FG1/II \\
\hline RN 2 & $\mathrm{~F}$ & 56 & 10 & $\mathrm{OP} / \mathrm{DH}$ & FG1/II \\
\hline RN 3 & $\mathrm{~F}$ & 42 & 19 & $\mathrm{OP} / \mathrm{DH}$ & FG1/II \\
\hline RN 4 & F & 55 & 15 & I & FG1/II \\
\hline RN 5 & F & 35 & 8 & I & FG1/II \\
\hline RN 6 & $\mathrm{~F}$ & 39 & 7 & I & FG1/II \\
\hline RN 7 & $\mathrm{~F}$ & 53 & 25 & $\mathrm{OP} / \mathrm{DH} / \mathrm{I}$ & FG2/II \\
\hline $\mathrm{RN} 8$ & $\mathrm{~F}$ & 31 & 8 & $\mathrm{OP} / \mathrm{DH} / \mathrm{I}$ & FG2/II \\
\hline RN 9 & F & 40 & 9 & I & FG2/II \\
\hline RN 10 & $\mathrm{~F}$ & 37 & 7 & $\mathrm{OP} / \mathrm{DH} / \mathrm{I}$ & FG2/II \\
\hline RN 11 & $\mathrm{~F}$ & 34 & 5 & $\mathrm{OP} / \mathrm{DH} / \mathrm{I}$ & FG2/II \\
\hline RN 12 & $\mathrm{~F}$ & 31 & 7 & $\mathrm{OP} / \mathrm{DH} / \mathrm{I}$ & $\mathrm{FG} 2 / \mathrm{II}$ \\
\hline RN 13 & F & 41 & 12 & $\mathrm{OP} / \mathrm{DH} / \mathrm{I}$ & II \\
\hline RN 14 & F & 37 & 7 & $\mathrm{OP} / \mathrm{DH} / \mathrm{I}$ & II \\
\hline
\end{tabular}

$R N$ registered nurse, $O P$ outpatient consultations, $D H$ day hospital, $I$ inpatients, $F G$ focus group, $I I$ individual interviews

families, which varied according to the types of relationships within the family (Q15). They witnessed the quality of the family's presence: from extreme investment and omnipresence to avoidance and even absence (Q16, Q17). Constant presence was also perceived as a source of anxiety and fatigue for the patient (Q18).

Finally, they perceived themselves as a mediator, an interface, in the relationship between the patient and the physician. They considered themselves more available and more approachable than the physician and therefore closer to the patient. This mediation consisted in comforting the patient after bad news and in translating biomedical information (Q19). A mediator's role can be delicate, and the nurses sometimes faced questions that seemed to them to belong to physicians, especially concerning death (Q20). They also played the role of an active mediator in the patient's relationships with family and friends, facilitating conversations (Q21).

Q10: RN 10 FG 2: "Most often, it's us at ringside." Q19: RN 6 FG1: "We have to be the interpreter sometimes..."

\section{Being}

Nurses also had to deal with questions about themselves, not only as professional healthcare providers but also as individuals (Q22, Q23). Similarly, the involvement of their own bodies called attention to the importance of physical contact in their relationships with patients (Q24).

Q22: RN 6 II: "I'm not just a robot who performs a procedure; I'm a whole person, ok? When I go into the room...there's not only the nurse - there's me, Vanessa."

\section{Emotional Distress in Their Practice}

Emotional distress occupied a central role in these nurses' experience. A major issue in providing care was what they could do with this distress and how they could handle it.

\section{Nurses' Emotional Distress}

They reported emotional distress related to their management of the relational distance and as a mirror of their patients' distress. They also described what we might call the paradigm of hospital nights.

\section{Emotional Distress and Management of Relational Distance} The nurses reported that distress increased with their closeness to the patient. They thus had to find the right relational distance for each patient: sufficiently far to protect themselves and close enough to be able to provide care $(\mathrm{Q} 25)$. They underlined the importance of a barrier in the relationship to protect themselves from depressive and anxious emotions, to establish a clear separation between their personal and their professional lives (Q26, Q27). Some nurses described "keeping a distance" and not becoming involved in a relationship with patients as a voluntary process (Q28). Nonetheless, most found themselves in situations where they were too close and too involved; it was very difficult to maintain an appropriate relational distance from the patient as the relationship developed, so that it became increasingly hard to maintain the person/nurse barrier (Q29, Q30).

Q27: RN 12 II: “I put a barrier, it's the job! It's not easy but, there, when I leave sometimes, I'm going to think about it a little, but, well, I have my life to live." 
Table 3 quotations

1. Nurses' practices: seeing, smelling, doing, interacting, being

1.1 Seeing

1.2 Smelling

1.3 Doing

1.4 Interacting

1.5 Being

2. Emotional distress in their practice

2.1 Nurses' emotional distress
Q1: RN 3 II: "The body is eaten away, bitten into, you can see it, physically... for internal lesions, you can imagine necrosis inside, but this, you really see it there... the cancer is there, it's eating away, it's growing."

Q2: RN7 II: "Everything that's visible, that is, the face... it's more... terrible because what's left, at the most, you can put a bandage, you cannot see it anymore... You cover the face, it's ok."

Q3: RN5 FG1: "What's a problem is when there's a smell, when it really smells awful... You cannot help but grimace."

Q4: RN 8 II: "When I go into the room and there's this smell, I cannot keep myself from thinking of cancer, of what's waiting for them... It's not easy to hide our emotions from these patients because sometimes the smell is too strong."

Q5: RN 1 FG 1: "We apply, we have the patient who's been seen by the doctor, we apply the protocol... We are the stingers!"

Q6/ RN 7 II: "They come to do chemo, it's the technical procedures first!"

Q7: RN 1 II: "I take the material, like the tongs... a compress... I put it between me and the lesion, in fact."

Q8: RN 2 II: "I try...to put myself in the situation of a professional and...to take care of people, of their bodies... even though these sights aren't very pretty."

Q9: RN 13 II: "You have to touch there because...for the person, it's important to not be disgusted, because... that's a part of them, and you have to take care of it."

Q10: RN 10 FG 2: "Most often, it's us at ringside."

Q11: RN 3 II: "We try to be there to support them...especially to listen to them... Being there and paying attention to their needs and saying to them, here, you are not alone because we are here... They do not necessarily want to talk, they just need you to be there."

Q12: RN 4 FG1: "They [family and close friends] come with the patient... They are part of managing the patient."

Q13: RN 2 FG1: "They can have lots of questions and then when the doctor comes, the questions do not".

Q14: RN 4 II: "When the physician arrives, he [the patient] is afraid... Will there be good news, or not?"

Q15: RN 1 FG1: "There are families who only function by what they do not say... There are very open families who say everything."

Q16: RN 13 II: "There are families who are 100\% invested, there. I remember one relative of a patient who slept there, who heated up food, who washed the patient. Who was really there all the time, all the time."

Q17: RN 2 FG1: "There are family members who totally avoid, who do not talk, who come very little, who are afraid."

Q18: RN 5 FG1: "She can never stay alone, calm... She told us that she was tired, that she had all the time in the world and that she'd like to rest, in peace... She needs some privacy."

Q19: RN 6 FG1: "We have to be the interpreter sometimes..."

Q20: RN 5 FG1: "We're not supposed to give them important information like that. And I'm stuck with this question. What should I tell them?"

Q21: RN 4 FG1: "The relationship between the two [patient and family member] is not simple. But finally, they both know it. And so...we try to keep between them."

Q22: RN 6 II: "I'm not just a robot who performs a procedure; I'm a whole person, ok? When I go into the room...there's not only the nurse - there's me, Vanessa."

Q23: RN 1 II: "We're not just nurses, we are also men, women, and we understand their feelings."

Q24: RN 7 II: "It's dumb, but I touch him, I touch his hand, his foot...to show that I am physically there too."

Emotional distress and management of relational distance

Q25: RN 4 II: "I feel that you should not cry either, but you have to show that you are sympathetic."

Q26: RN 3 FG1: "We end up, nonetheless, putting a barrier between them and us... otherwise we would necessarily be completely depressed, given everything that goes on here, we could not hang on."

Q27: RN 12 II: "I put a barrier, it's the job! It's not easy but, there, when I leave sometimes, I'm going to think about it a little, but, well, I have my life to live."

Q28: RN 1 FG1: "When it can be difficult, that's when we protect ourselves more. But finally, we give less."

Q29: RN 14 II: "I try to not be too empathetic but it's not always easy in fact; there are moments when you leave the room in tears, because you are already attached to the person."

Q30: RN 10 II: "They come regularly, you know their whole history, the whole family history, and so perhaps you step back a little less and then, we are humans. So, we more or less have a chemistry with some patients, with some families and sometimes it's not always easy to keep our distance."

Nurses' distress: reflection of the patient's distress

Q31: FN 2 FG1: "Personally I let myself be submerged by all these feelings... I was the same age so....really, I identify with them."

Q32: RN 1 II: "To say to yourself that one day it will be us, that it is also our fears of death." 
Table 3 (continued)

1. Nurses' practices: seeing, smelling, doing, interacting, being

\begin{tabular}{|c|c|}
\hline & $\begin{array}{l}\text { Q33: RN } 3 \text { II: "In the evening, they hold my hand and then they say, "oh do not go." I say, "you do not want to be } \\
\text { alone.” They find themselves alone in the room, facing themselves, and I think there are some who find it } \\
\text { hard.” } \\
\text { Q34: RN } 7 \text { II: "We do not just feel like we are all alone, we are all alone." } \\
\text { Paradigm of hospital nights } \\
\text { Q35: RN } 1 \text { II: "Are they going to die during the night? It's that. Are they going to wake up? It's that. They do not } \\
\text { say, "are we going to die?" but rather "are we going to wake up?"” } \\
\text { Q36: RN } 8 \text { FG2: "The stress of the night!" } \\
\text { Q37: RN } 5 \text { FG1: "The difficult situations, when it's late in the evening, the doctors are gone, there's a patient who } \\
\text { is not consoled; and we know we are going to take over for the night, and that they are going to have a terrible } \\
\text { night... Emotions are exacerbated... The night is going to be difficult... You feel it!" }\end{array}$ \\
\hline $\begin{array}{l}\text { 2.2 Strategies to protect against } \\
\text { emotional distress }\end{array}$ & 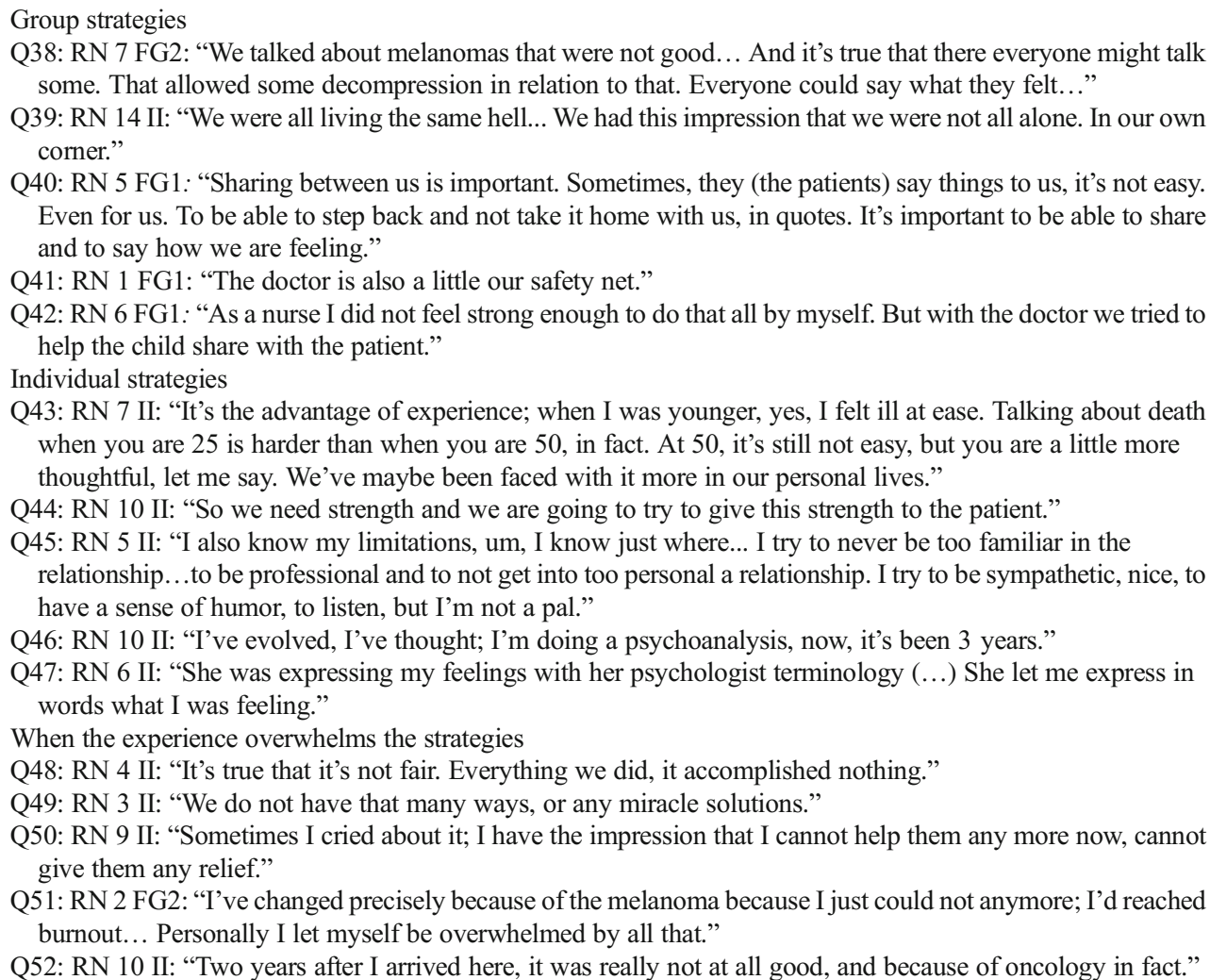 \\
\hline
\end{tabular}

Nurses' Distress: Reflection of the Patient's Distress Their distress thus appeared indissociable from that of their patients, and they described it as "identification with the patient"(Q31). They described in a similar fashion the patients' anguish about death and their own, and a distress associated with solitude for their patients and themselves (Q32, Q33, Q34).

Q31: FN 2 FG1: "Personally I let myself be submerged by all these feelings... I was the same age so...really, I identify with them."

Paradigm of Hospital Nights They reported the especially anxiety-inducing atmosphere of the hospital at night for the patients, as their feelings of anxiety and solitude increased and the emotional experience intensified (Q35, Q36). Similarly, the night appeared to be a paradigm of the stakes of their own emotional management of their work (Q37).

Q36: RN 8 FG2: "The stress of the night!"

\section{Strategies to Protect Against Emotional Distress}

The nurses described both group and individual strategies they used to cope and protect themselves from this distress and its repercussions in their personal lives.

Group Strategies They underlined the importance of organized group support in structured settings, such as 
departmental meetings and training days. These spaces allowed them to express themselves, to share their difficulties, and thus to not feel alone (Q38, Q39). They also reported many more informal, spontaneous discussions, which they considered to be an effective barrier that helped prevent work from invading their personal lives (Q40). In addition, they stressed support from physicians, whom they described as "safety net" (Q41, Q42).

Q40: RN 5 FG1: "Sharing between us is important. Sometimes, they (the patients) say things to us, it's not easy. Even for us. To be able to step back and not take it home with us, in quotes. It's important to be able to share and to say how we are feeling."

Individual Strategies The nurses also relied on individual strategies, in particular their personal but also their professional experience, for example, the need to be strong as a person in order to be able to be strong as a nurse (Q43, Q44). This required knowledge of themselves and of their limitations (Q45). Some mentioned the utility of individual psychotherapy as a space for self-reflection and verbalization of emotions (Q46, Q47).

Q46: RN 10 II: “I've evolved, I've thought; I'm doing a psychoanalysis, now, it's been 3 years."

When the Experience Overwhelms the Strategies When these strategies were not effective, some nurses reported situations of emotional exhaustion, expressed in feelings of uselessness and injustice against disease, and of helplessness and insignificance in the face of disease and death (Q48, Q49, Q50). Some described situations of burnout related to cancers with the worst prognoses (Q51). They associated their work in dermatologic oncology directly with their exhaustion (Q52).

Q51: RN 2 FG2: 'I've changed precisely because of the melanoma because I just couldn't anymore; I'd reached burnout... Personally I let myself be overwhelmed by all that."

\section{Discussion}

Our results show some of the elements described for nursing practice in general and for oncology in particular: the predominant role of supportive care through relationships and the issues linked to the emotional distress experienced by nurses because of their closeness to patients. The interpersonal dimension of the relationship between nurse and patient has already been pointed out $[11,12]$. What we observe in our population is compassion fatigue, where nurses, deeply involved in the relationship and the provision of care, are overwhelmed by their patients' fears and anxiety [21]. It can precede or accompany burnout syndrome [22]. Both conditions have been explored among nurses [23], especially those providing oncology care [24].

Two particularly original results merit comment here: (i) the specificities associated with skin cancer and (ii) the dynamic interaction between individual and group stances as effective strategies to protect against distress.

Experience with the appearance and odor of skin cancer is a specific aspect of the work of the nurses in our study. They face the harrowing experience of cancer that is seen and smelled and must deal with its frightening and destructive visibility; it induces anxiety and distress. These specificities have not been reported in the literature. Only one study, which measured the risks of burnout and satisfaction at work of dermatology nurses, has concluded that they have a lower risk of burnout than nurses in other departments [25]. Our results show the distress provoked by this wrenching experience of skin cancer could impede nurses' supportive care role as it is a specific risk factor for compassion fatigue or burnout in nurses in dermatology departments providing care to patients with skin cancer. This distressful experience described here in this specific context can be transposed to any other situations where oncology nurses are providing care to patient with a cancer that can be seen or smelled, such as advanced and recurrent breast cancer - with the sight and fetid odor emanating from ulcerated tumors- $[26$, 27], extensive tumors of the head or neck - very often with a fetid odor- [28], or rectal cancer [29].

The other original result is the dynamic interaction between individual and group stances as strategy for preventing and treating compassion fatigue in oncology nurses. The nurses alternate between an individual stance (their person, their experience, their personality) and a group stance (their professional identity, their peer groups, their care techniques) to cope with the anguish of their patients. In their narratives, they oscillated continuously between the personal "I" and the professional "we"; they understand care and their relationship with their patient simultaneously as individuals and as a group entity. This individual/group dynamic, not previously described in the literature, enables nurses to maintain a good relational distance and to avoid the invasion of their personal space. When the emotional burden becomes too great and individual nurses are too involved, they can use their professional group identity and the technical know-how that this group shares. That is, to protect themselves from the anxiety induced by the sight and smell of the cancer, nurses use their work group as support and mobilize techniques of care, to provide care. This dynamic individual/group strategy is different from those previously described for preventing and treating compassion fatigue in oncology nurses. They can be 
oriented toward the staff member personally (individual psychotherapy, work/life balance), toward professional practices (supervision time, seminars to develop awareness), and also toward the nurses' organization of work (patient/nurse ratio, workload, work environment) [23, 24].

Our results also show the paradigmatic situation of hospital nights. In this context, nurses cannot implement the dynamic individual/group strategy and show more difficulties to provide supportive care to the patients with skin cancer. They are most exposed to their solitude when they are least able to use the group as support [30]. The physiological mechanisms associated with the circadian rhythm, which may intensify feelings of fear, may be added to this [31]. This specific dynamic of the experience of nurses at night is an original result of our study, which has not previously been reported.

Our results allow us to consider specific clinical implications focusing on the issue of the odor of cancer. This odor is distressful for both patients and nurses. Thus, oncology nurses should receive specific training about management of malodorous wounds, as solutions do exist [32], to overcome this experience and be able to provide supportive care by creating a collaborative process with the patient to deal with this specific issue. Moreover, this individual/group dynamic might not be specific to dermatology oncology nursing care but could also be described in various oncology nursing care settings. Further research is needed. Complementary studies are also needed to explore the specific experience of nurses on night duty. Finally, future research on the experience of nurses in dermatologic oncology could usefully examine the question of sight and smell, which are associated with especially anxiety-inducing aspects of nurses' practices in this context.

\section{Limitations}

Our study has some limitations. First, in our sample, all the nurses were women. Our results cannot be extended to the experience of male nurses. Second, even thought our results underline the preponderant relational dimension of healthcare provision, this study examines only the perspective of nurses. It is necessary to collect the experience of other protagonists in this situation - dermatologists, patients, and family, to be able to cross these different perspectives. Finally, this is a singlecenter study from a single perspective.

The strength of our study lies in the triangulation of the data collection methods simultaneously combining focus groups and individual interviews. This method may have influenced our results. The collection of data in focus groups and individual interviews reproduced the individual/group dynamic found in the nurses. We think that this combination of these two methods had a heuristic function in our study and enabled the emergence of the role of this dynamic in the nurses' management of emotions and relational distance.
Acknowledgments We would like to thank all the nurses who participated and JA Cahn for the translation.

\section{Compliance with Ethical Standards}

Conflict of Interest The authors declare that they have no conflicts of interest.

\section{References}

1. Gandhi SA, Kampp J (2015) Skin cancer epidemiology, detection, and management. Med Clin N Am 99(6):1323-1335

2. Xiang F, Lucas R, Hales S, Neale R (2014) Incidence of non melanoma skin cancer in relation to ambient UV radiation in white populations, 1978-2012: empirical relationships. JAMA Dermatol 150(10): 1063-1071

3. Leiter U, Eigentler T, Garbe C (2014) Epidemiology of skin cancer. Adv Exp Med Biol 810:120-140

4. Selman LE, Beynon T, Radcliffe E, Whittaker S, Orlowska D, Child F, Harding R (2015) 'We're all carrying a burden that we're not sharing': a qualitative study of the impact of cutaneous T-cell lymphoma on the family. Br J Dermatol 172(6):1581-1592

5. Ribas A, Hamid O, Daud A, Hodi FS, Wolchok JD, Kefford R, Robert C (2016) Association of pembrolizumab with tumor response and survival among patients with advanced melanoma. JAMA 315(15):1600-1609

6. McMullen L (2013) Oncology nurse navigators and the continuum of cancer care. Semin Oncol Nurs 29(2):105-117

7. Saltmarsh K, De Vries K (2008) The paradoxical image of chemotherapy: a phenomenological description of nurses' experiences of administering chemotherapy. Eur J Cancer Care 17(5):500-508

8. De Silva BS, Rolls C (2011) Attitudes, beliefs, and practices of Sri Lankan nurses toward cancer pain management: an ethnographic study: cancer pain and nursing in Sri Lanka. Nurs Health Sci 13(4): 419-424

9. Dewey A, Dean T (2008) Nurses' management of patients with advanced cancer and weight loss: part 2. Int J Palliat Nurs 14(3): $132-138$

10. Olsson C, Berglund AL, Larsson M, Athlin E (2012) Patient's sexuality - a neglected area of cancer nursing? Eur J Oncol Nurs 16(4): 426-431

11. Banning M, Gumley VA (2012) Clinical nurses' expressions of the emotions related to caring and coping with cancer patients in Pakistan: a qualitative study. Eur J Cancer Care 21(6):800-808

12. Iranmanesh S, Axelsson K, Sävenstedt S, Häggström T (2009) A caring relationship with people who have cancer. J Adv Nurs 65(6): 1300-1308

13. Ekedahl M, Wengström Y (2006) Nurses in cancer care-coping strategies when encountering existential issues. Eur J Oncol Nurs 10(2):128-139

14. Tong A, Sainsbury P, Craig J (2007) Consolidated criteria for reporting qualitative research (COREQ): a 32-item checklist for interviews and focus groups. Int J Qual Health Care 19(6):349-357

15. Patton MQ (2002) Qualitative research and evaluation methods. Sage, Thousand Oaks

16. Britten N (2013) Chapter 2 Qualitative interviews. In: Pope C, Mays N (eds) Qualitative research in health care, 3rd edn. Blackwell Pub./BMJ Books, Malden

17. Creswell J (2000) Determining validity in qualitative inquiry. Theory Pract 39(3):124-131

18. Lambert SD, Loiselle CG (2008) Combining individual interviews and focus groups to enhance data richness. J Adv Nurs 62:228-237. https://doi.org/10.1111/j.1365-2648.2007.04559.x 
19. Dey I (1999) Grounding grounded theory: guidelines for qualitative inquiry. Academic Press, San Diego

20. Braun V, Clarke V, Terry G (2014) Chapter 7 Thematic analysis. In: Rohleder P, Lyons AC (eds) Qualitative research in clinical and health psychology. Palgrave Macmillan

21. Coetzee SK, Klopper HC (2010) Compassion fatigue within nursing practice: a concept analysis: concept analysis of compassion fatigue. Nurs Health Sci 12(2):235-243

22. Maslach C, Leiter MP (1997) The truth about burnout: how organizations cause personal stress and what to do about it. Wiley

23. van Mol MC, Kompanje EJO, Benoit DD, Bakker J, Nijkamp MD (2015) The prevalence of compassion fatigue and burnout among healthcare professionals in intensive care units: a systematic review. PLoS One 10(8):e0136955

24. Najjar N, Davis LW, Beck-Coon K, Carney DC (2009) Compassion fatigue: a review of the research to date and relevance to cancer-care providers. J Health Psychol 14(2):267-277

25. Renzi C, Tabolli S, Ianni A, Di Pietro C, Puddu P (2005) Burnout and job satisfaction comparing healthcare staff of a dermatological hospital and a general hospital. J Eur Acad Dermatol Venereol 19(2):153-157

26. Kuge S, Tokuda Y, Ohta M, Okumura A, Kubota M, Ninomiya S, Sawamura S, Makuuchi H, Tajima T, Mitomi T (1996) Use of metronidazole gel to control malodor in advanced and recurrent breast cancer. Jpn J Clin Oncol 26:207-210. https://doi.org/10. 1093/oxfordjournals.jjco.a023215
27. Rodrigues FT, Klemig LR, Cardozo MRP et al (2017) Myiasis associated with an invasive ductal carcinoma of the left breast: case study. Rev Inst Med Trop São Paulo:59. https://doi.org/10.1590/ s1678-9946201759035

28. Brusis T, Luckhaupt H (1989) Fetor from ulcerated head and neck tumors: causation and therapy. Ann Otol Rhinol Laryngol 98:615617. https://doi.org/10.1177/000348948909800809

29. Kuy S, Romero RAL, Vincent L, Rose K (2017) Images: perineal pain and malodorous drainage in a patient with rectal cancer. Postgrad Med J 93:51-52. https://doi.org/10.1136/postgradmedj2016-134210

30. Salzmann-Erikson M, Lagerqvist L, Pousette S (2016) Keep calm and have a good night: nurses' strategies to promote inpatients' sleep in the hospital environment. Scand J Caring Sci 30(2):356364

31. Li Y, Ma W, Kang Q, Qiao L, Tang D, Qiu J, Li H (2015) Night or darkness, which intensifies the feeling of fear? Int J Psychophysiol 97(1):46-57

32. Sedlak J, Chheda S, Green C, Okoh E, Zhelu Z (2014) Malodor management in high exuding chronic wounds. In IEEE, p 1-3. https://doi.org/10.1109/NEBEC.2014.6972933

Publisher's Note Springer Nature remains neutral with regard to jurisdictional claims in published maps and institutional affiliations. 